\title{
Minimization of Torque Ripple in Switched Reluctance Motor Drives Using an Enhanced Direct Instantaneous Torque Control
}

\author{
J. Castro, P. Andrada, B. Blanqué
}

\begin{abstract}
Torque ripple is an inherent characteristic of switched reluctance motor drives due to its double salient geometry and it is a serious drawback in applications that require smooth torque and high dynamic performances. This paper presents new contributions to the minimization of torque ripple in SRM using an enhanced direct instantaneous torque control. Torque ripple is reduced by adding a PI controller before the instantaneous torque controller and a change in the commutation zones. The PI direct instantaneous torque controller (PI+DITC) is simulated using Matlab/Simulink and then implemented in a DSPACE ACE kit 1006 CLP. Finally, experimental results are shown and they are compared with those obtained using conventional direct instantaneous torque control.
\end{abstract}

Index Terms -- Switched reluctance motor, torque ripple, direct torque control

\section{INTRODUCTION}

$\mathrm{T}$ $\mathrm{HE}$ switched reluctance motor (SRM) is gaining recognition in the electric drive market due to its simple and rugged construction, low expected manufacturing cost, fault tolerance capability, high efficiency and high torque to inertia ratio. Despite these advantages, the SRM has some disadvantages: it requires an electronic control and shaft position sensor, a huge capacitor is needed in the DC link and the double salient structure causes noise and torque ripple. Torque ripple is a serious drawback of SRM in applications that require smooth torque and high dynamic performances. Up to now, some mechanical design solutions have been proposed for minimizing torque ripple although they usually reduce the maximum torque and have a limited range of operation. Torque ripple can be minimized over a wider operating range by using electronic torque control techniques. These techniques can be classified in [1-7]:

Indirect (controlled variable current or flux linkage)

- Current profiling with off-line calculation of profiles

- Current profiling with on-line calculation of profiles

- Flux linkage profiling with off-line calculation of profiles

- Harmonic injection

Direct (controlled variable instantaneous torque)

- Instantaneous torque control

This paper presents new contributions to the minimization of torque ripple in SRM using an enhanced

The authors are with Electronically Commutated Drives Group (GAECE). Departament d'Enginyeria Elèctrica (DEE). Escola Politècnica Superior d'Enginyeria de Vilanova I la Getrú (EPSEVG). Universitat Politècnica de Catalunya (UPC) BARCELONATECH. Avinguda Victor Balaguer 1, Vilanova i la Geltrú 08800, Spain (e-mail: pere.andrada@upc.edu) direct instantaneous torque control (DITC). The rest of paper is organized as follows: section 2 describes the fundamentals of the direct torque control of SRM, section 3 presents the proposed new PI+DIT controller, section 4 presents de simulation mode in Matlab-Simulink section, 5 shows the experimental results and compares them with those obtained using a conventional DIT controller, and finally section 6 presents the conclusions drawn from this research.

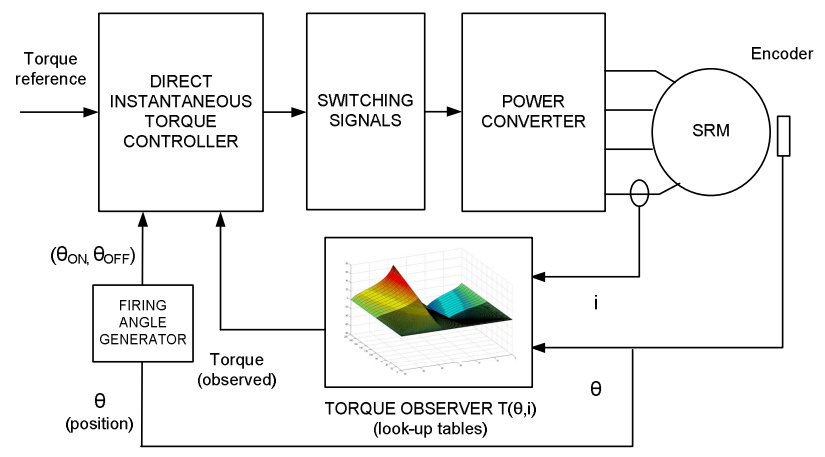

Fig. 1. Block diagram of a DITC of the SRM

\section{FUNDAMENTALS OF DIT CONTROLLER}

The block diagram of a DITC of SRM is shown in Fig. 1. The instantaneous torque value is estimated from terminal variables (current and position) by means of a look up table $\mathrm{T}(\theta, \mathrm{i})$ that has been previously computed using FLUX, a finite element analysis software [8-9]. The torque-currentposition profile obtained by finite element analysis for the four phases SRM prototype, whose main data are listed in the appendix, is given in Fig. 2. Obviously, if the SRM prototype is available, it is best to obtain the torque-currentposition profile experimentally and store these values in the look up table $\mathrm{T}(\theta, \mathrm{i})$.

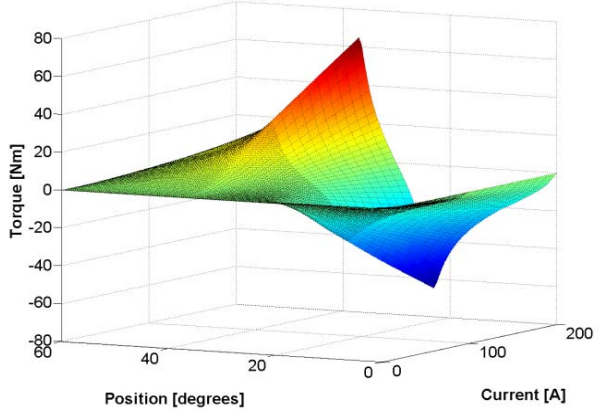

Fig. 2. Torque-current-position profile of the SRM prototype

Then, the estimated or measured value of torque is compared with the reference torque, for certain firing 
angles $\left(\theta_{\mathrm{ON}}, \theta_{\mathrm{OFF}}\right)$, in a direct instantaneous torque controller that generates the appropriate switching signals of the power converter. Firing angles are selected from a look up table according to the operation conditions (torque and speed). The power converter, in this case a four phases asymmetric converter with two power switches and two diodes per phase, has three states, which are denominated magnetization state (Vcc), freewheeling state (fw) and demagnetization state (-Vcc).

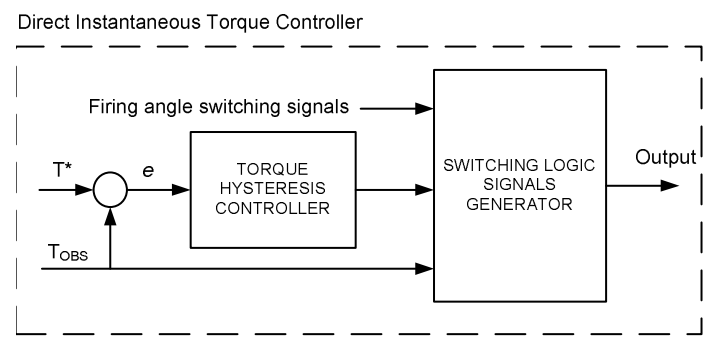

Fig. 3. Block diagram of DIT controller (per phase)

The working principle of the DITC is based on phase overlap to compensate the fall of torque due to the phase commutation. The outgoing phase begins its demagnetization state, reducing the torque value, and the incoming phase is not able to provide enough torque to maintain a regular value until reaching a certain current value. The intelligent core of DITC is the generator of switching logic signals, which combines the firing angles switching signals and the torque hysteresis regulator signals to produce the appropriate control signals to the power converter switches, Fig.3.

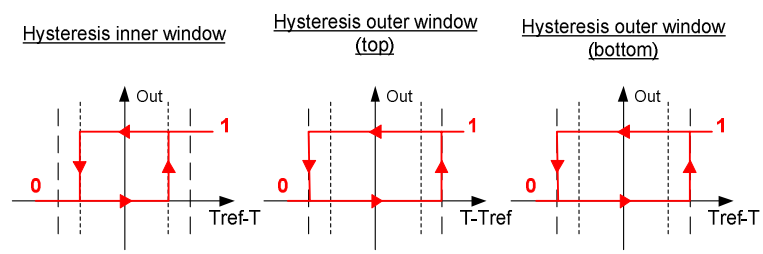

Fig. 4. Diagram of the hysteresis controllers

Once the conducting zones are defined, torque ripple control actions are given by the torque hysteresis controller, which consists of three hysteresis controllers that compare the torque reference value with the estimated one, Fig.3. To maintain a desired torque value and reduce the ripple, two hysteresis windows are set: an inner one for conduction in ZONE 2, and an outer one for conduction in ZONE 3. Fig. 4 shows the three different torque hysteresis regulators and its window values. The outer window produces higher torque ripple but allows the outgoing phase demagnetization to finish before entering the negative torque production region. Fig. 5 demonstrates the DITC working principle. The active phase (continuous line) stays in ZONE 2 up to the instant $t_{1}$, when begins the phase overlap and it becomes the outgoing phase. In this period, the active phase is the only torque producer and its values are contained within the outer window, because is the inner window torque hysteresis regulator the producer of the torque demand signals. From the instant $t_{1}$ up to $t_{2}$ (ZONE 3 ), the incoming phase (dotted line) becomes the main torque producer, and the outgoing phase has an auxiliary role adding or subtracting the necessary torque to maintain the torque value within a desired range. When the torque value exceed the outer window the outgoing phase reduces the total torque value producing negative torque $(-\mathrm{Vcc})$, also producing positive torque $(+\mathrm{Vcc})$ when the incoming phase is not able to produce enough torque and total torque value falls over the outer band. Finally, at the instant $t_{2}$, the end of conduction period of the outgoing phase is reached, entering in ZONE 1 when phase is demagnetized. The cycle continues with the active phase (dotted line) and the next phase.

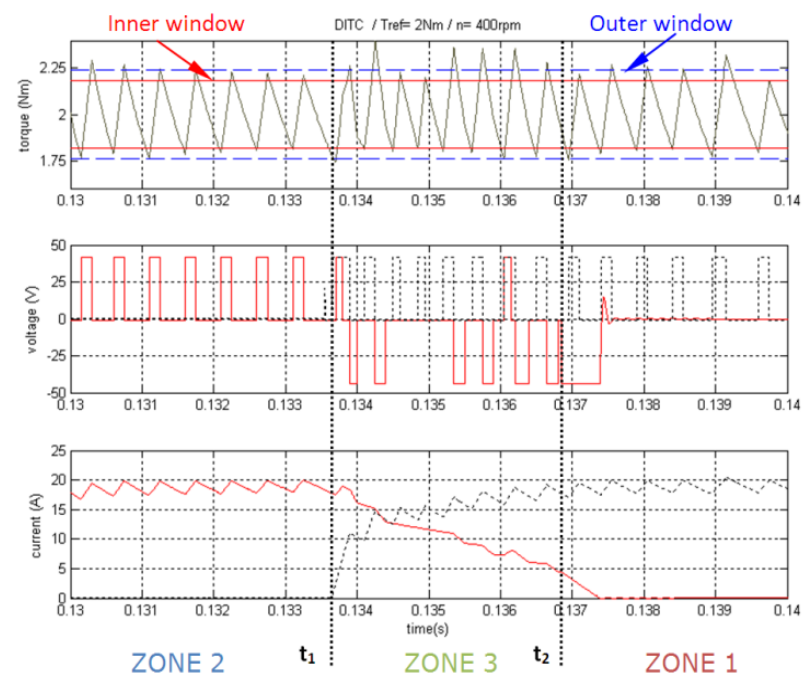

Fig. 5. DITC, waveforms of instantaneous torque, voltage and current in which the different zones considered in the commutation process and the two hysteresis bands (windows) have been represented

The main advantage of the DIT controller is its simplicity consequence of the use of hysteresis regulators. But in these regulators, switching frequency can not be controlled therefore high sampling frequencies are required to lock up the torque within the prefixed windows. In practice, for a giving sample frequency of the digital system where the DIT controller has been implemented, torque is out, at some instants, the range delimited by the hysteresis windows.

\section{NEW DIT CONTROLLER}

Some improvements are introduced in order to mitigate the drawbacks of the DIT controller.

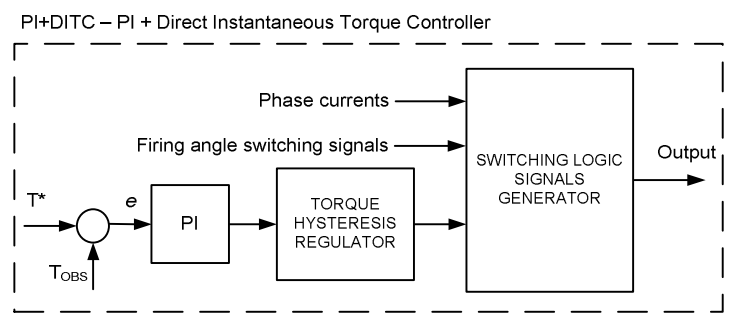

Fig. 6. Block diagram of PI+DIT controller (per phase)

Torque ripple can be reduced by adding a PI controller before the torque hysteresis regulator. On one hand, the proportional gain will produce higher error values, and consequently, an earlier response of the hysteresis regulators. On the other hand, the integral gain will contribute to reduce the steady state error. Thus, the instantaneous torque controller is anticipating to future 
torque values, being able to perform the proper actions to avoid exceeding the desired ripple limits. A block diagram of the new controller, called PI + DIT controller, is shown in Fig. 6. Other improvement implemented in this controller is a change in the conduction zones. ZONE 2 remains the same, only one phase is conducting until the overlap region starts, however, ZONE 3 has changed significantly. In the $\mathrm{PI}+\mathrm{DIT}$ controller the end of ZONE 3 is not defined by the firing angles, but is defined by the current value of the incoming phase (continuous line). When the incoming phase current is higher than the outgoing phase current (dotted line), this last reaches the demagnetization state (ZONE 1). This action will increase the energy returned to the voltage source, improving the drive efficiency. Fig.7 shows the waveforms considering this new working principle.
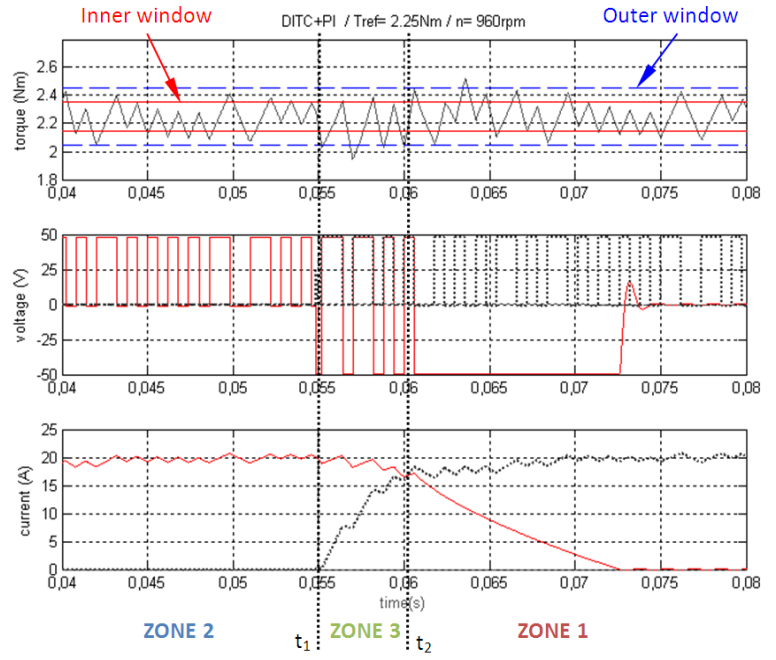

Fig. 7. Waveforms of instantaneous torque, voltage and current in which the different zones considered in the commutation process and the two hysteresis bands have been represented (PI+DITC).

In Fig. 8 torque error values are compared between the conventional and the improved PI+DITC.
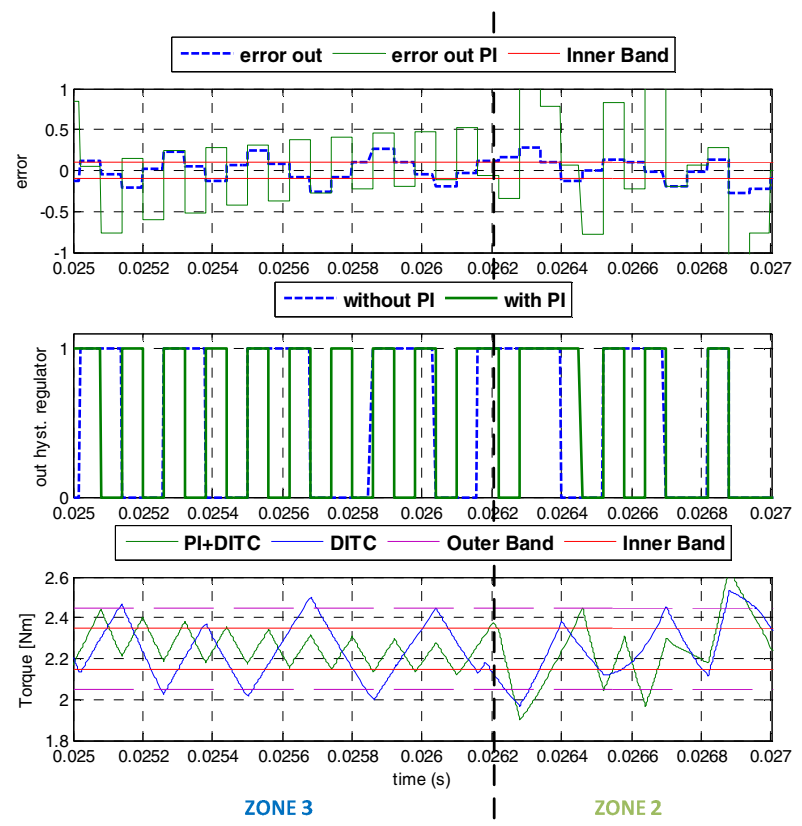

Fig. 8. Torque error values (DITC vs. PI+DITC), inner window torque hysteresis regulator signals (DITC vs. PI+DITC) and instantaneous torque (DITC vs. PI+DITC)

\section{Simulation MODEl OF THE PI+DIT CONTROLLER}

The simulation environment used has also been Matlab/Simulink since control models can be directly implemented in a rapid-prototyping board. The simulation model for this new controller is based on DITC model explained in [9]. Fig. 9 shows the PI+DITC block diagram according to the structure depicted in Fig. 6, with the PI block for improving the system performance.

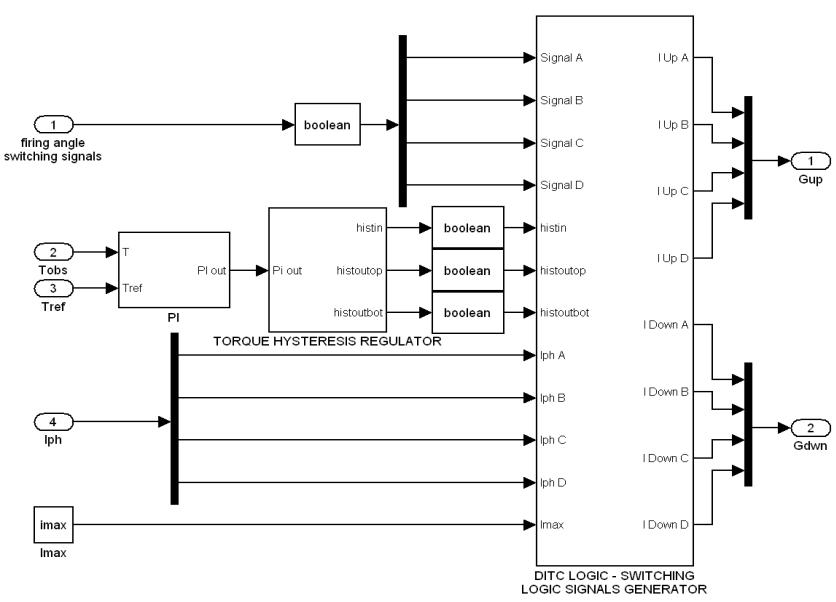

Fig. 9. Simulink block diagram of the PI+DITC

The generator of switching logic signals is detailed in Fig. 10, where a finite-state Mealy machine performs the logic combination of signals, references and states to generate the proper control signals to the power converter switches.

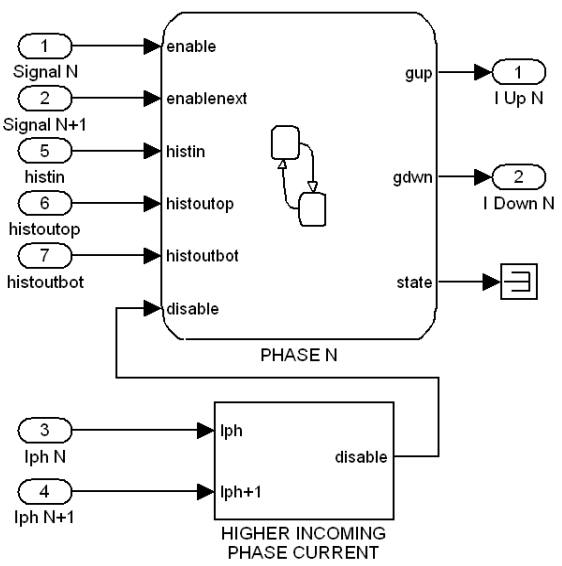

Fig. 10. Block diagram of the generator of switching logic signals (per phase

The code implemented in the Mealy machine differs from DIT controller [10], as a consequence of the deactivation of the outgoing phase when the incoming phase current is higher than the outgoing phase current. The structure of the finite-state machine is represented by a flowchart as is depicted in Fig. 11. Inside each conduction zone, depending on the result of the decision nodes, the different states are reached $(+\mathrm{Vcc} / \mathrm{Vcc} / \mathrm{fw})$. Decision nodes histin, histout(bot) and histout(top) correspond to the torque hysteresis controller signals of inner, outer (bottom) and (top) windows. Simulation will also be useful to contrast the expected and the obtained experimental results. 


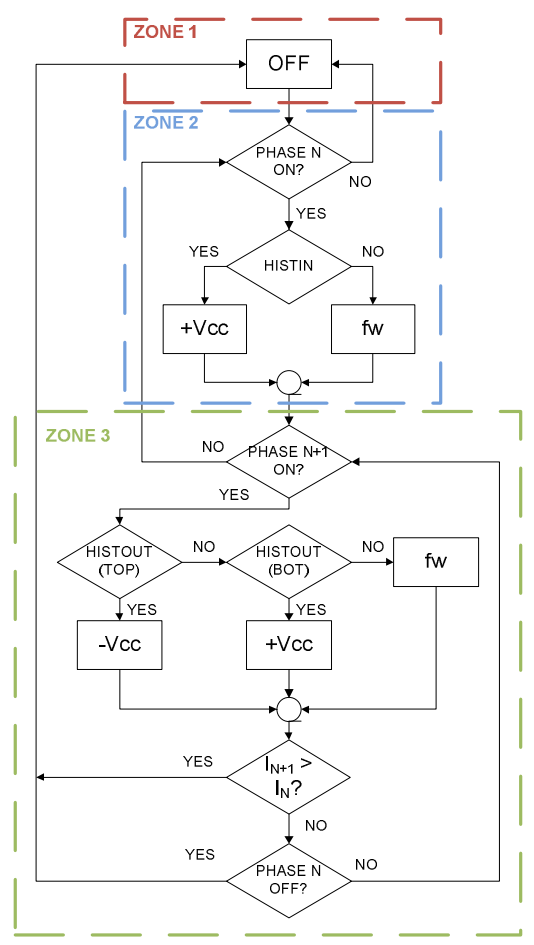

Fig. 11. Flowchart of the Mealy finite-state machine

\section{EXPERIMENTAL RESULTS}

The proposed PI+DITC was implemented in a real time testing platform a DSPACE ACE kit 1006 CLP that included a processor board with an AMD OpteronTM running at $2.6 \mathrm{GHz}$. The DSPACE ACE kit 1006 CLP is a rapid-prototyping tool that allows controllers to be designed in Simulink, a well-known simulation and prototyping environment for modeling dynamic systems. Once these controllers have been designed, the code is simply generated and loaded into a DSP for real-time control, thus allowing the control algorithm to be tested rapidly. The proposed PI+DITC was tested in a 8/6 SRM prototype, using a set up including the DSPACE ACE kit 1106 and a DC motor acting as a load, Fig 12. The experimental values of torque were obtained from the product of the torque constant by the instantaneous armature current of the DC motor, introducing the corrections to take into account the iron and mechanical losses of the DC motor at different speeds.

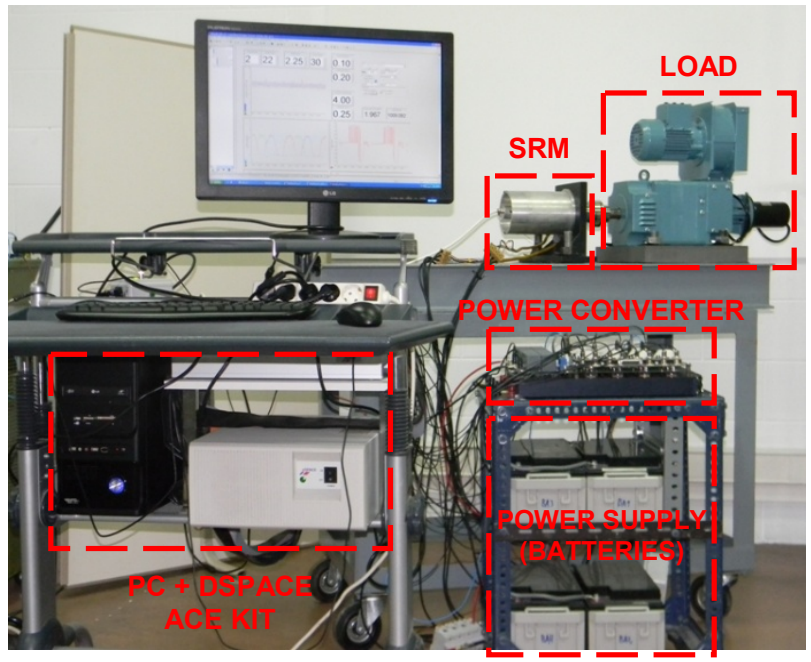

Fig. 12. Picture of the experimental setup
In Fig. 13 it can be seen a comparative between experimental and simulated results in both cases for an average torque of $2 \mathrm{Nm}$ and an inner and outer hysteresis windows of +0.1 and $+0.2 \mathrm{Nm}$ respectively. A comparative between PI+DITC and a conventional DITC for the same average torque is shown in Fig. 14.

\section{CONCLUSIONS}

This paper presents some contributions to the minimization of torque ripple in SRM using a new direct instantaneous torque control. The new direct torque adds a PI controller before the instantaneous torque controller and a change in the commutation zones. The PI direct instantaneous torque controller (PI+DITC) is simulated using Matlab/Simulink, previous Finite element analysis of the motor, and then implemented in a DSPACE ACE kit 1006 CLP that includes a processor board with an AMD OpteronTM running at $2.6 \mathrm{GHz}$. Experimental results are shown and they are compared with those obtained using conventional DIT control demonstrating the goodness of the proposed PI+DITC in SRM drives specially in low speed ranges.

\section{APPENDIX}

MAIN DATA OF SRM PROTOTYPE

\begin{tabular}{|c|c|}
\hline Stator pole number & 8 \\
\hline Rotor pole number & 6 \\
\hline Voltage (V) & 48 \\
\hline Power (W) & 500 \\
\hline Speed (rpm) & 1500 \\
\hline Air-gap (mm) & 0.35 \\
\hline Rotor air-gap diameter (mm) & 56 \\
\hline Stack length (mm) & 80 \\
\hline
\end{tabular}

\section{REFERENCES}

[1] I. Husain, "Minimization of torque ripple in SRM drives", IEEE Transactions on Industrial Electronics, vol. 49, no 1, 2002, pp. 2839.

[2] R.B. Inderka, R.W. De Doncker, "DITC - Direct instantaneous torque control of switched reluctance drives", IEEE Transactions on Industry Applications, vol.39, no 4, 2003, pp.1046-1051.

[3] C.R. Neuhaus, N.H. Fuengwarodsakul, R.W.De Doncker, "Predictive PWM-based direct instantaneous torque control of switched reluctance drives", Power Electronics Specialists Conference, June 2006, pp.1-7

[4] J. Liang, J. Ahn, D. Lee, "High performance hydraulic pump system using switched reluctance drive". International Conference on Electrical Machines and Systems, October 2007, pp. 1470-1474

[5] J. Liang, D.H. Lee, J.W. Ahn. "Direct instantaneous torque control of switched reluctance machines using 4-level converters". IET Electr. Power Appl. 2009, Vol.3, Iss. 4, pp. 313-323.

[6] A. Nishimiya, H.Goto, H.Guo, O. Ichinokura. "A Novel Torque Control for a SR motor EV". Proceedings of the 2008 International Conference on Electrical Machines, Paper ID 1176, pp 1-5

[7] I. Delgado. "Control de par en un motor SRM aplicado a a dirección asistida en vehículos eléctricos utilizando herramientas de prototipado rápido" (in spanish). Director. B. Blanqué. PFC EPSEVG, 2010.

[8] F.D'hulster, K.Stockman, R.J.M. Belmans, "Modelling of switched reluctance machines: state of the art", International Journal of Modelling and Simulation, vol. 24, no 4, 2004, pp. 214-223.

[9] FLUX user's manual, www.cedrat.com

[10] J.Castro, P.Andrada, B.Blanqué. "Minimization of torque ripple in switched reluctance motor drives using direct instantaneous torque control'. ICREPQ'12, Santiago de Compostela (Spain), paper no. 664. March 2012, 

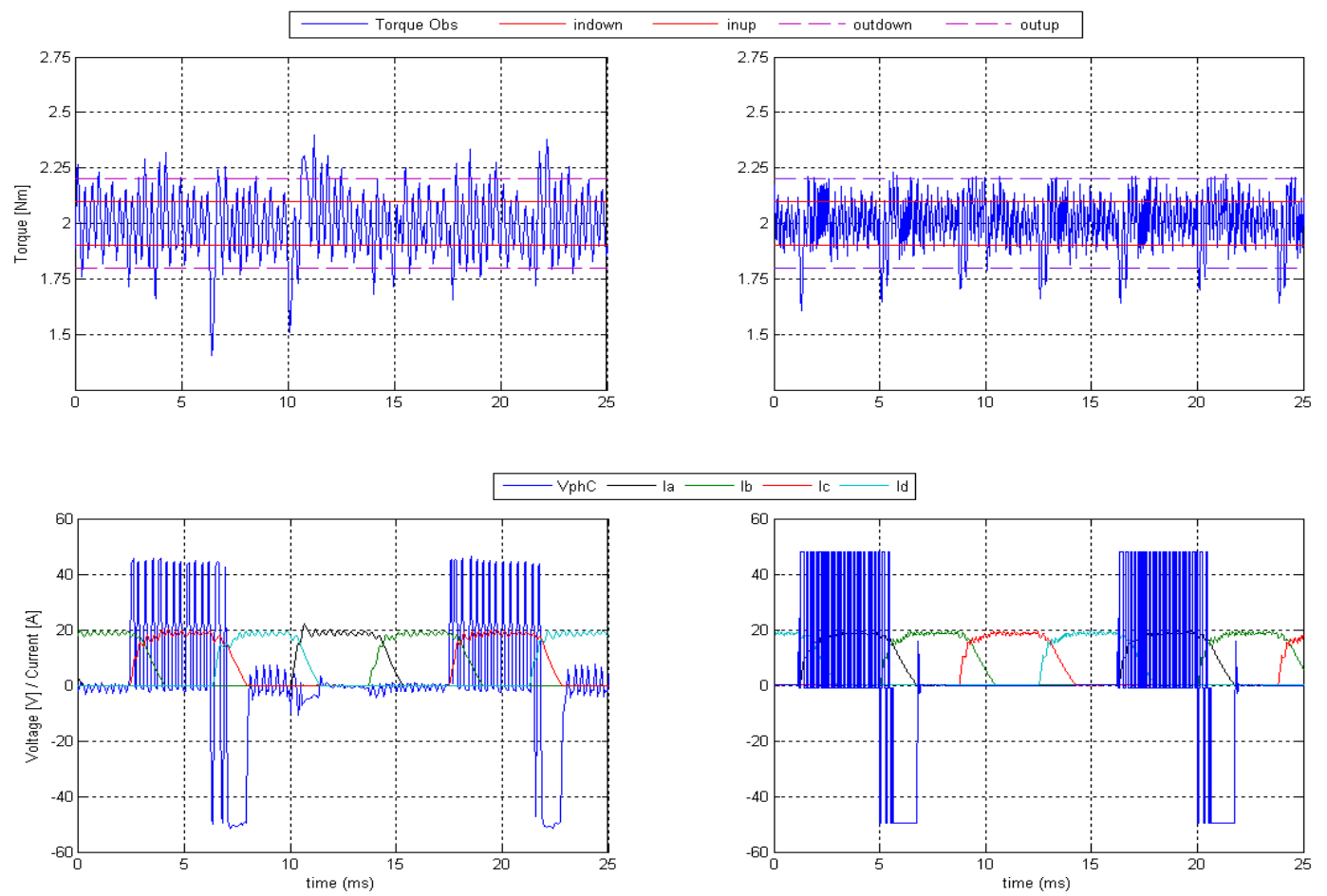

Fig. 13. PI+DITC experimental waveforms of torque, voltage and current (left) vs. simulation (right); in both cases average torque: 2 Nm, speed: 662 rpm, $\theta_{\mathrm{ON}}=3^{\circ}, \theta_{\mathrm{OFF}}=26^{\circ}$.
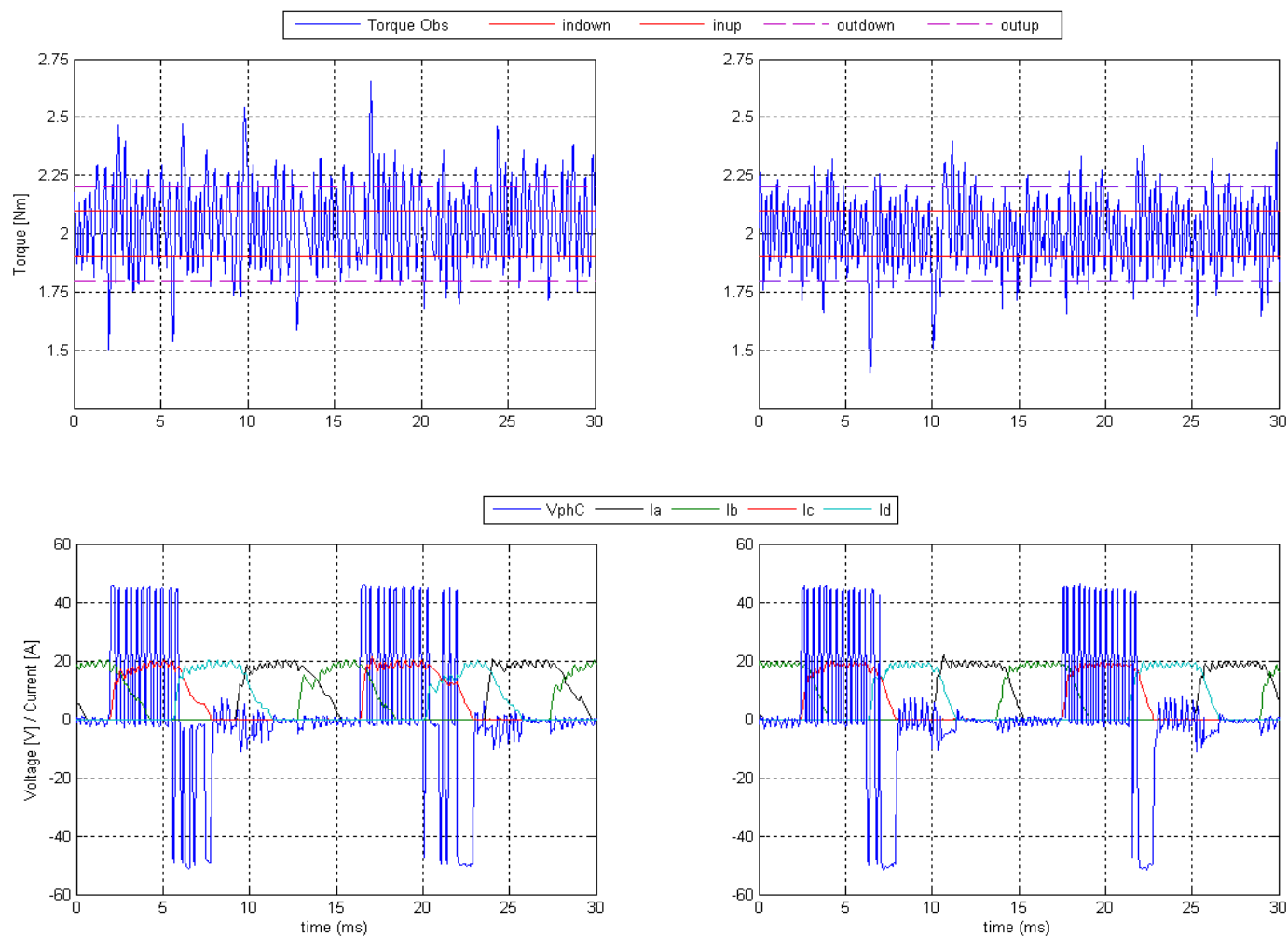

Fig. 14. Experimental waveforms of torque, voltage and current DITC (left) vs. PI+DITC (right); in both cases average torque: 2 Nm, speed: 662 rpm, $\theta_{\mathrm{ON}}=3^{\circ}, \theta_{\mathrm{OFF}}=26^{\circ}$. 


\section{BIOGRAPHIES}

Javier Castro received the B.S. degree in Electrical Engineering and the M.S. degree in Automation and Industrial Electronics, both from the Universitat Politècnica de Catalunya (UPC) in Barcelona, Spain, in 2007 and 2012, respectively. He is currently working toward the PhD. degree in Electrical Engineering at the Universitat Politècnica de Catalunya (UPC) BARCELONATECH. His research interests include modeling, simulation and control of electrical machines and drives

Pere Andrada received his MSc and PHD degrees in Industrial Engineering from the Universitat Politècnica de Catalunya (UPC) BARCELONATECH in Barcelona, Spain in 1980 and 1990 respectively. In 1980 he joined the Department of Electrical Engineering, Universitat Politècnica de Catalunya (UPC) where he is currently an Associate Professor in the Escola Politècnica Superior d'Enginyeria de Vilanova i la Geltrú (EPSVG). He is member of the Electronically Commutated Drives Group (GAECE). His teaching activities and research interests include design, modeling and control of electrical machines and drives.
Balduí Blanqué received the B.S. degree in Telecommunications, the M.S. degree in Telecommunications, and the Ph.D. degree from the Universitat Politècnica de Catalunya (UPC) BARCELONATECH, in Barcelona, Spain, in 1996, 1999, and 2007, respectively. Since 1996, he has been with the Department of Electrical Engineering, Universitat Politècnica de Catalunya (UPC), where he is currently an Assistant Professor in the Escola Politècnica Superior d'Enginyeria de Vilanova i la Geltrú (EPSVG). He is member of the Electronically Commutated Drives Group (GAECE). His teaching activities cover digital design and electronics applications and his research interests include modeling, simulation and control of electrical machines and drives. 